To the Editors:

\title{
Modified simple percutaneous suprapubic cystostomy
}

A kindergartener starts school and on the first day feels the urge to go to the bathroom. He was already shown where the boy's bathroom is in the hall, so he gets up and goes to the bathroom. When he returns, his teacher realizes she cannot chastise him for this action, as she neglected to tell the students that they must each raise a hand and ask permission to leave the room to use the bathroom. As he was not told going to the bathroom was not allowed without asking, the little boy had done nothing wrong. The next day, another little boy goes to the bathroom without permission. When he returns, his teacher asks why he has gone without asking as he had been told that was not allowed. He responds, "I just wanted to see what would happen if I did" [1].

Similarly, this surgical registrar (HDRCS) with an enquiring mind has successfully substituted the conventional open suprapubic cystostomy with the technique he describes [2], in a busy casualty operating session, wondering "I just want to see what would happen if I do this modification". Such a departure from well established surgical technique requires a great measure of boldness and pragmatism. I applaud him for this endeavour and let his innovative thinking and enthusiasm be contagious.

\section{References}

1. Goldstein I. The extremes of sexual medicine (editorial). Journal of Sexual Medicine 2009; 6 (1): 4-6.

2. Siriwardana HDRC. Modified simple percutaneous suprapubic cystostomy. Ceylon Medical Journal 2008; 53 (4): 138-9.

Serozsha A S Goonewardena, National Hospital of Sri Lanka, Colombo. E-mail: <drsasgurol@yahoo.com>. 